\title{
Volcanic contribution to decadal changes in tropospheric temperature
}

\author{
Benjamin D. Santer ${ }^{1 \star}$, Céline Bonfils ${ }^{1}$, Jeffrey F. Painter ${ }^{1}$, Mark D. Zelinka ${ }^{1}$, Carl Mears ${ }^{2}$, \\ Susan Solomon ${ }^{3}$, Gavin A. Schmidt ${ }^{4}$, John C. Fyfe ${ }^{5}$, Jason N. S. Cole ${ }^{5}$, Larissa Nazarenko ${ }^{4}$, \\ Karl E. Taylor ${ }^{1}$ and Frank J. Wentz ${ }^{2}$
}

\begin{abstract}
Despite continued growth in atmospheric levels of greenhouse gases, global mean surface and tropospheric temperatures have shown slower warming since 1998 than previously ${ }^{1-5}$. Possible explanations for the slow-down include internal climate variability $3,4,6,7$, external cooling influences ${ }^{1,2,4,8-11}$ and observational errors ${ }^{12,13}$. Several recent modelling studies have examined the contribution of early twenty-first-century volcanic eruptions $s^{1,2,4,8}$ to the muted surface warming. Here we present a detailed analysis of the impact of recent volcanic forcing on tropospheric temperature, based on observations as well as climate model simulations. We identify statistically significant correlations between observations of stratospheric aerosol optical depth and satellite-based estimates of both tropospheric temperature and short-wave fluxes at the top of the atmosphere. We show that climate model simulations without the effects of early twenty-first-century volcanic eruptions overestimate the tropospheric warming observed since 1998. In two simulations with more realistic volcanic influences following the 1991 Pinatubo eruption, differences between simulated and observed tropospheric temperature trends over the period 1998 to 2012 are up to 15\% smaller, with large uncertainties in the magnitude of the effect. To reduce these uncertainties, better observations of eruption-specific properties of volcanic aerosols are needed, as well as improved representation of these eruption-specific properties in climate model simulations.
\end{abstract}

Our analysis uses satellite measurements of changes in the temperature of the lower troposphere (TLT) made by Microwave Sounding Units (MSU) on National Oceanic and Atmospheric Administration (NOAA) polar-orbiting satellites ${ }^{13,14}$. Satellite TLT data have near-global, time-invariant spatial coverage; in contrast, global-mean trends estimated from surface thermometer records can be biased by spatially and temporally non-random coverage changes $^{15}$. We compare MSU TLT data with synthetic satellite temperatures ${ }^{3}$ calculated from simulations performed under phase 5 of the Coupled Model Intercomparison Project ${ }^{16}$ (CMIP-5). These ALL +8.5 simulations include estimated historical (1850-2005) and future (2006-2100) changes in combined anthropogenic and natural external forcings (Supplementary Tables 1-3).

Although our primary focus is on the recent 'warming hiatus', we also examine volcanically induced changes in warming rate following the eruptions of El Chichón (April 1982) and Pinatubo (June 1991). Both volcanic events increased stratospheric loadings of liquid-phase sulphate aerosols, leading to stratospheric warming and tropospheric cooling ${ }^{17-19}$ (Supplementary Fig. 1). Stratospheric temperature recovers within 1-2 years after El Chichón and Pinatubo. As a result of the large thermal inertia of the ocean, the recovery of tropospheric temperatures is slower (about 8-10 years; refs 20,21).

To analyse volcanic contributions to observed changes in warming rates, it is useful to reduce the amplitude of internal noise $\mathrm{e}^{20-22}$. Our noise reduction strategy involves removing the temperature signal of the El Niño/Southern Oscillation (ENSO), a leading mode of internal climate variability. ENSO variability is characterized here by a commonly used index of sea surface temperature changes in the eastern equatorial Pacific ${ }^{23}$. We remove ENSO effects from the satellite data and CMIP-5 simulations with an iterative regression-based method, which accounts for correlation between the predictor variables used to estimate ENSO and volcano temperature signals (Supplementary Figs 2 and 3 and Supplementary Methods) $)^{20,21}$.

Removing ENSO markedly improves the agreement between the observed and the model average temperature responses to major volcanic eruptions (compare Fig. 1a with b). When both ENSO and volcano influences are subtracted, the model and observed temperature residuals have very similar low-frequency changes up to the end of the twentieth century (Fig. 1c). After 1999, however, a 'warming hiatus' is still apparent in the observed residual TLT time series, but the lower troposphere continues to warm in the CMIP-5 multi-model average.

This difference between modelled and observed warming trends must be partly due to treatment of twenty-first-century volcanic forcing in the CMIP-5 ALL+8.5 simulations $^{1,2,4}$. In the real world, 17 'small' eruptions occurred after 1999 (refs 1,24,25; Fig. 2a and Supplementary Table 4). The impact of each of these eruptions on the estimated stratospheric aerosol optical depth (SAOD) is an order of magnitude smaller than that of Pinatubo (Supplementary Fig. 4A). The cumulative effect of these successive twenty-firstcentury eruptions, however, was to increase global-mean SAOD by $4 \%-7 \%$ annually from $2000-2009$ (refs $1,24,25$ ). This increase in SAOD is not included in any of the ALL +8.5 simulations, which assume that SAOD decayed to background values or zero ${ }^{1,4}$ by the year 2000.

Over $50 \%$ of the larger twenty-first-century volcanic events occurred in the tropics ${ }^{24,25}$ (Fig. 2a). The largest eruptions seem to have discernible signatures in satellite estimates of the tropical net

\footnotetext{
${ }^{1}$ Program for Climate Model Diagnosis and Intercomparison (PCMDI), Lawrence Livermore National Laboratory, Livermore, California 94550, USA, ${ }^{2}$ Remote Sensing Systems, Santa Rosa, California 95401, USA, ${ }^{3}$ Massachusetts Institute of Technology, Earth, Atmospheric, and Planetary Sciences, Cambridge, Massachussets 02139, USA, ${ }^{4}$ NASA/Goddard Institute for Space Studies, New York, New York 10025, USA, ${ }^{5}$ Canadian Centre for Climate Modelling and Analysis, Environment Canada, Victoria, British Columbia V8W 2Y2, Canada. *e-mail: santer1@llnl.gov
} 

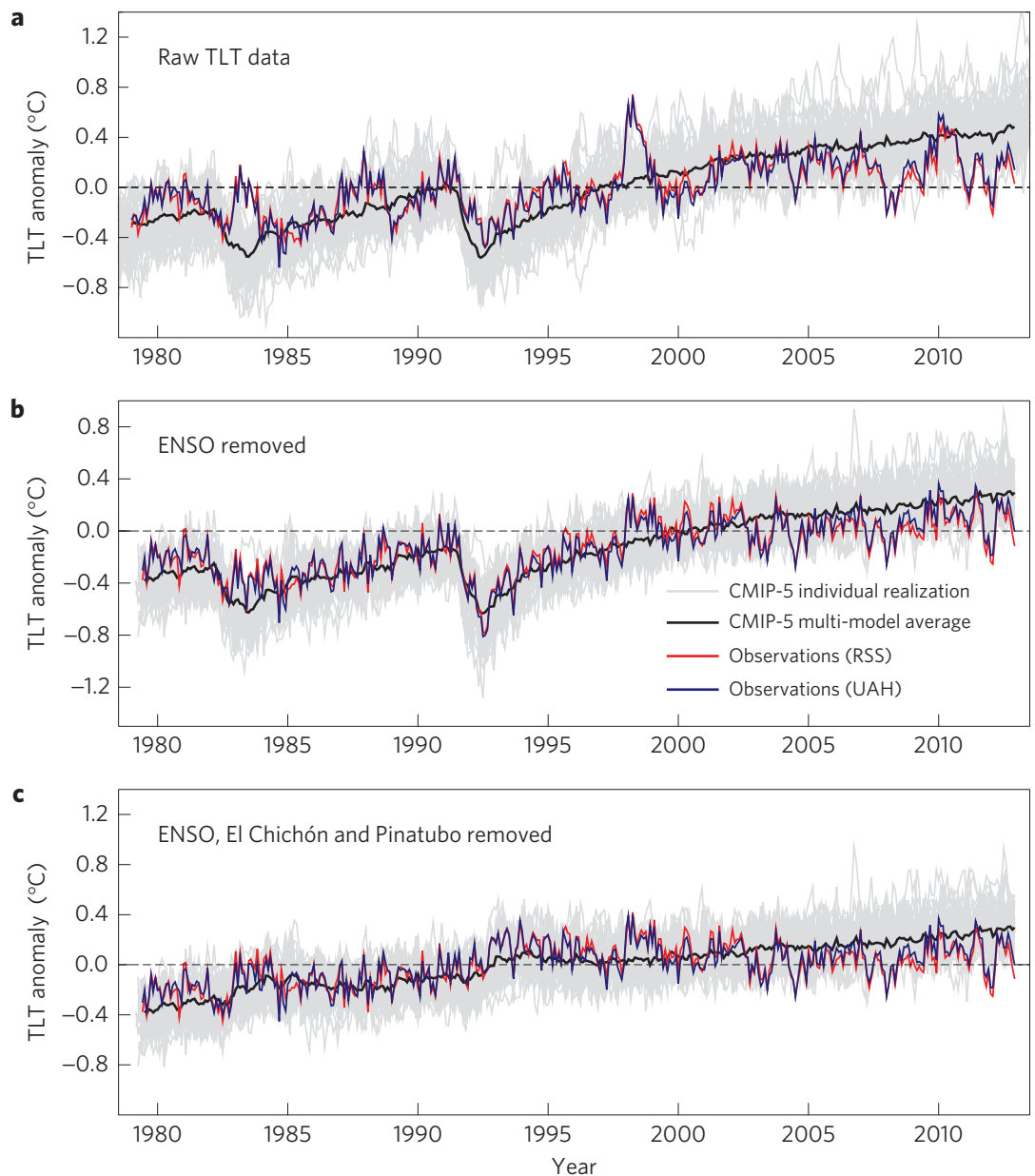

Figure 1 | Modelled and observed near-global $\left(82.5^{\circ} \mathrm{N}-70^{\circ} \mathrm{S}\right)$ monthly mean TLT anomalies before and after statistical removal of ENSO and volcano signals. a, The original TLT anomalies are departures from the climatological monthly means over January 1979-December 2012. b, Removal of the estimated ENSO signal in TLT reduces the noise that partially obscures the temperature response to the eruptions of El Chichón and Pinatubo. c, Subtraction of the ENSO, El Chichón and Pinatubo signals from the original TLT data yields the temperature residuals.

clear-sky short-wave (SW) radiation at the top of the atmosphere ${ }^{26}$ and in the 'ENSO removed' tropical TLT data (Fig. 2b,c). The SW signatures arise because volcanic aerosols reflect part of the incoming solar radiation back to space. The increase in tropical net clear-sky SW radiation over January 2001-December 2012 (by roughly $0.25 \mathrm{~W} \mathrm{~m}^{-2}$ per decade) is qualitatively consistent with the independently estimated SAOD increase over this period.

Even after statistical removal of ENSO effects, there is still considerable internal variability in tropical TLT (Fig. 2c). We perform two statistical tests to determine whether recent volcanic eruptions have cooling signals that can be discriminated from this residual variability. First, our 'individual eruption' tests (Fig. 3a) consider whether there are statistically significant changes in tropical TLT after eight of the larger volcanic eruptions in a recently developed observational SAOD data set ${ }^{24}$. Significance is assessed by comparing the estimated observed cooling signal of each eruption with appropriate null distributions of TLT changes. These 'no volcanic signal' distributions were obtained from 10,000 synthetic TLT time series generated by a lag- 1 autoregressive statistical model (Supplementary Methods).

For Pinatubo, the cooling of the tropical lower troposphere is consistently significant at the $1 \%$ level for all 12 sets of processing choices (combinations of averaging period for estimating the preeruption temperature and post-eruption cooling). The tropical TLT signals of Manam, Tavurvur and Nabro are significant at the 10\% level or better, but only for certain combinations of processing choices. No averaging period choices explored here yield statistically significant cooling after Nevado del Ruiz, Kelut, Sarychev or Merapi.

Our second test addresses the statistical significance of correlations between SAOD and 'ENSO removed' TLT data (Fig. 3b). As volcanic activity is inherently non-stationary, the correlation $r$ \{SAOD, TLT $\}$ between SAOD and TLT is sensitive to the selected analysis period. We account for non-stationarity in $r\{\mathrm{SAOD}, \mathrm{TLT}\}$ using a 60-month 'moving window' analysis. As in the case of the cooling signals of individual eruptions, we assess the significance of $r$ \{SAOD, TLT $\}$ by generating null distributions of this statistic (Supplementary Methods).

The most significant negative values of $r\{\mathrm{SAOD}, \mathrm{TLT}\}$ occur during 60-month periods that encompass the pronounced SAOD increase and TLT decrease after Pinatubo (Fig. 3b). Moving windows that sample the post-2004 SAOD and TLT changes also yield statistically significant $r\{\mathrm{SAOD}, \mathrm{TLT}\}$ values (at the $10 \%$ level or better). Taken together, the results from our 'individual eruption' and $r$ SAOD, TLT $\}$ tests suggest that internally generated variability could plausibly explain some of the observed tropical TLT changes after individual 'small' eruptions, but is less likely to explain the observed synchronicity between multiple twenty-first-century eruptions and multiple tropospheric cooling signals.

We also calculate $r\{\mathrm{SAOD}, \mathrm{SW}\}$, the contemporaneous correlations between overlapping 60-month segments of observational SAOD and net clear-sky SW radiation time series. For the tropical SAOD and SW changes in the early twenty-first 


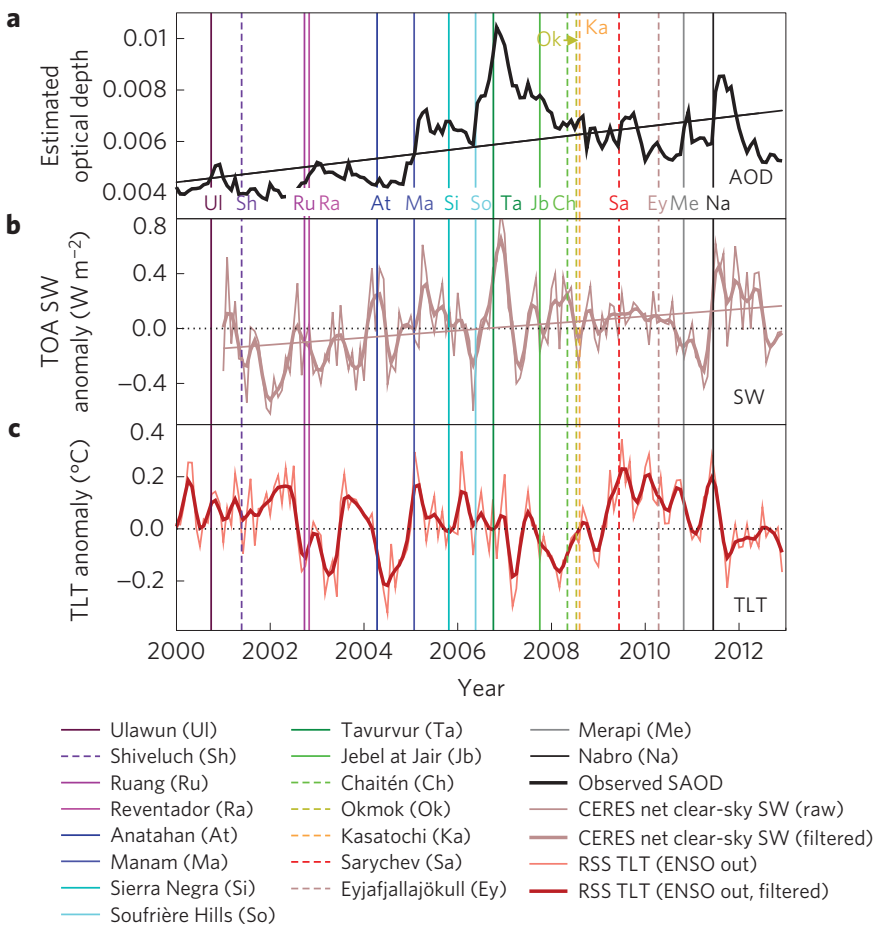

Figure 2 | Effect of recent volcanic eruptions on atmospheric temperature. a-c, Changes in observed SAOD ${ }^{24}$ (a), net clear-sky SW radiation at the top of the atmosphere ${ }^{26}$ (b) and 'ENSO removed' TLT data ${ }^{13}$ (c). Results are spatially averaged over the tropics $\left(20^{\circ} \mathrm{N}-20^{\circ} \mathrm{S}\right)$. A five-term binomial filter was used to produce the smoothed results (bold lines) in $\mathbf{b}, \mathbf{c}$. Vertical lines denote the dates of the eruptions listed in Supplementary Table 4. Solid and dashed vertical lines indicate eruptions that occurred within or outside the $20^{\circ} \mathrm{N}-20^{\circ} \mathrm{S}$ latitude band, respectively.

century, values of $r\{\mathrm{SAOD}, \mathrm{SW}\}$ consistently attain significance at the $5 \%$ level or better (Fig. 3b), providing independent confirmation of the $r\{\mathrm{SAOD}, \mathrm{TLT}\}$ results. Our findings for near-global changes in SAOD, TLT and SW (Supplementary Fig. 5) are similar to those shown here for the tropics.

To better understand the contributions of late twentieth- and early twenty-first-century volcanic forcing to global-scale changes in tropospheric warming rates, we calculate maximally overlapping 10 -year trends from the 'ENSO removed' TLT time series in Fig. $1 \mathrm{~b}$. This simple smoothing procedure ${ }^{3}$ reveals that observed and model average TLT changes are remarkably similar, both in phase and in amplitude, for the first 20 years of the satellite record (Fig. 4). In contrast, model 10-year TLT trends are larger than observed for trends with start dates after 1993.

The twin trend maxima in Fig. 4 are related to the temperature responses to El Chichón and Pinatubo. Each eruption is followed by a 13- to 14-month cooling phase until maximum monthly mean cooling $\left(\Delta T_{\max }\right)$ is attained (Fig. 1b). Tropospheric warming during the slow recovery from El Chichón and Pinatubo augments the more gradual warming trend arising from human-caused increases in greenhouse gases. This is why 10-year TLT trends that begin close to the time of $\Delta T_{\max }$ have large positive values. These results clearly show that El Chichón and Pinatubo had important impacts on decadal changes in warming rates, despite statements to the contrary ${ }^{27}$.

It has been claimed that the recent divergence between modelled and observed temperature changes provides evidence that CMIP-5 models are (on average) 2-3 times too sensitive to human-caused changes in greenhouse gases ${ }^{28}$. If this claim is correct, there is a serious error in present model-based estimates of the transient

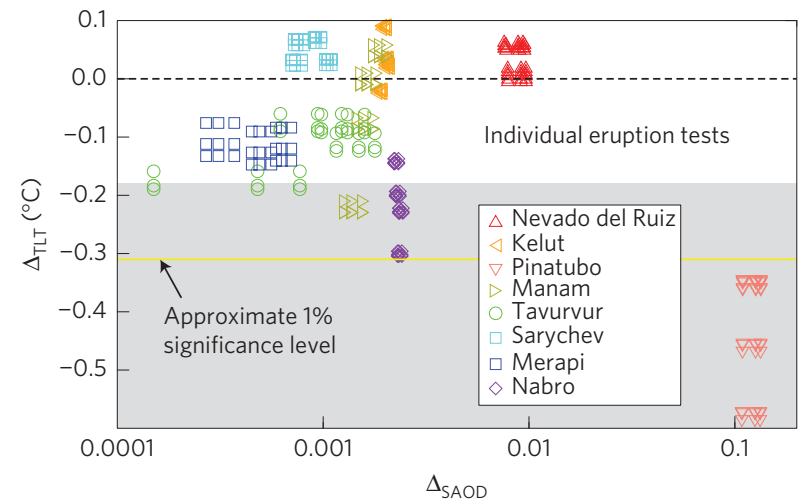

b

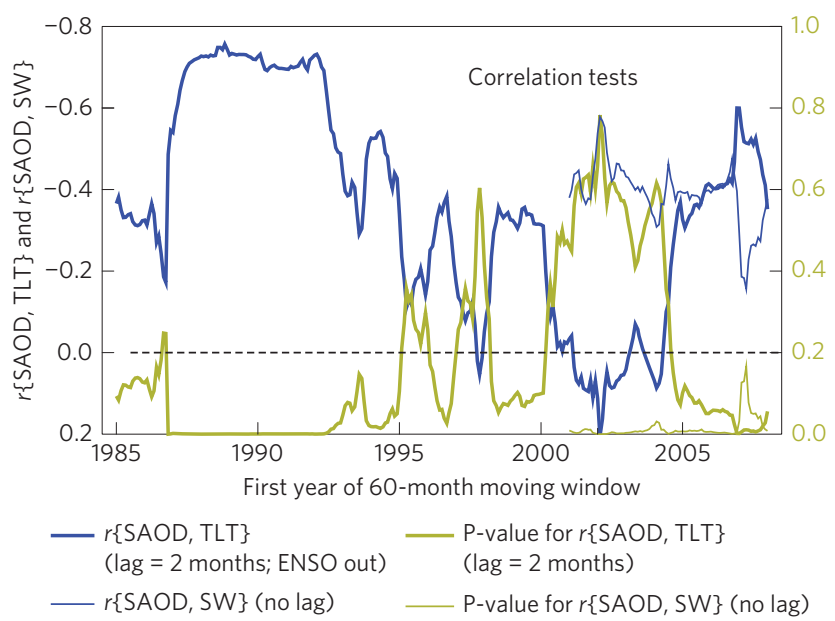

Figure 3 | Statistical significance of observed tropical $\left(20^{\circ} \mathrm{N}-20^{\circ} \mathrm{S}\right)$ climate signals after late twentieth- and early twenty-first-century volcanic eruptions. a, Estimated observed changes in SAOD (ref. 24; $\Delta_{\text {SAOD }}$ ) and 'ENSO-removed' TLT (ref. 13; $\Delta_{\text {TLT }}$ ) after 8 individual eruptions. For each eruption, there are 36 different combinations of $\Delta_{S A O D}$ and $\Delta_{T L T}$, calculated with different lengths of averaging period for determining pre- and post-eruption changes. Values of $\Delta_{\mathrm{TLT}}$ within the grey shaded area are statistically significant at the $10 \%$ level or better; values below the yellow line are significant at the $1 \%$ level. $\mathbf{b}, r\{S A O D, T L T\}$, the lagged correlations between monthly mean observational time series of SAOD and TLT, and $r\{S A O D, S W\}$, the contemporaneous correlations between SAOD and net clear-sky SW radiation ${ }^{26}$. Values of $r\{S A O D, T L T\}$ and $r\{S A O D, S W\}$ were computed using a 60-month moving window, with an overlap of 59 months between successive analysis periods. As observed SW time series are shorter than TLT records, $r\{S A O D, S W\}$ can be shown only for 60-month periods beginning after 2000. The sign of $r\{S A O D, S W\}$ was changed to facilitate display with $r\{S A O D, T L T\}$ results. The statistical significance of $r\{\mathrm{SAOD}, \mathrm{TLT}\}$ and $r\{\mathrm{SAOD}, \mathrm{SW}\}$ is indicated on the alternative $y$ axis of $\mathbf{b}$. The significance tests applied in $\mathbf{a}, \mathbf{b}$ are described in the Supplementary Methods.

climate response (TCR) to greenhouse gas forcing. As both TCR and the volcanic signal decay time $\tau$ (Methods) are related to the rate of ocean heat uptake ${ }^{20}$, a large model error in ocean heat uptake would yield errors in the simulated temperature response to El Chichón and Pinatubo. The close agreement we find between the observed and model average TLT responses to El Chichón and Pinatubo (Fig. 4) does not support the claim of a fundamental model error in climate sensitivity.

On the basis of the results presented here, we argue that the divergence of modelled and observed low-frequency TLT changes over the final 15 years of the satellite record is partly due to systematic errors in the post-Pinatubo volcanic forcing in the ALL +8.5 simulations. Three model-based studies ${ }^{1,2,8}$ find that the 


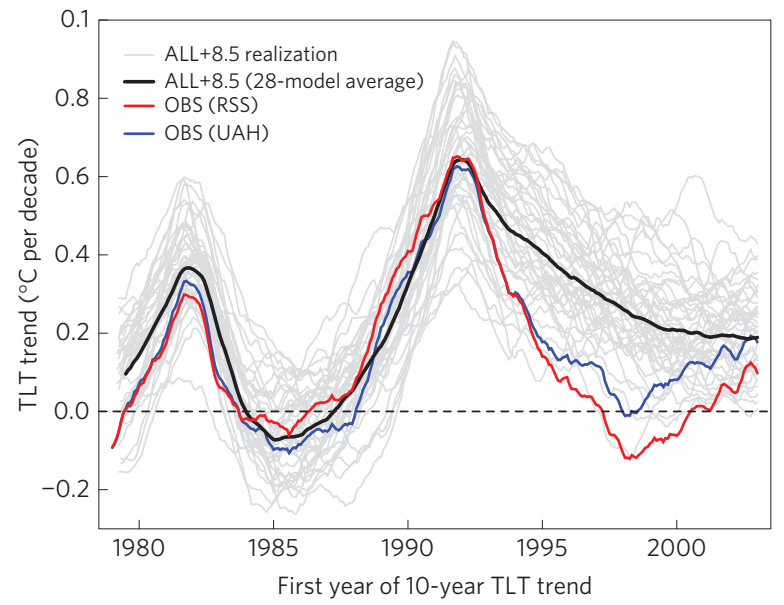

Figure 4 | Behaviour of overlapping 10-year trends in the 'ENSO removed' near-global $\left(82.5^{\circ} \mathrm{N}-70^{\circ} \mathrm{S}\right)$ TLT data. Least-squares linear trends were calculated over 120 months, with overlap by all but one month; that is, the first trend is over January 1979-December 1988, the second trend over February 1979-January 1989, and so on. The last trend is over January 2003-December 2012.

inclusion of more realistic post-Pinatubo volcanic forcing reduces global-mean surface temperature by 0.02 to $0.07^{\circ} \mathrm{C}$ by 2010 . We obtain qualitatively similar results (Supplementary Fig. 6). We analysed simulations with improved representation of the observed SAOD changes after Pinatubo (ALL+ Vol21c). These were performed with the GISS-E2-R and CanESM2 models developed at the Goddard Institute for Space Studies and Canadian Centre for Climate Modelling and Analysis (respectively).

After ENSO removal, the discrepancy between the observed TLT trends over 1998-2012 and the corresponding trends in the $\mathrm{ALL}+\mathrm{Vol} 21 \mathrm{c}$ ensemble averages is reduced by $2-4 \%$ (GISS-E2-R) or by $11-15 \%$ (CanESM2), depending on which observational data set is selected. These estimates vary because of model differences in: the imposed post-Pinatubo SAOD changes, and whether SAOD is allowed to decay back to near-zero after Pinatubo (Supplementary Fig. 4A); the decisions made in translating SAOD changes into volcanic aerosol forcing; TCR and equilibrium climate sensitivity; the amplitude and phase of internal climate variability; and the treatment of other (non-volcanic) external forcings.

Better quantification of the contribution of recent volcanic forcing to the 'warming hiatus' will require new model simulations, and more detailed analysis of the seasonal and regional attributes of modelled and observed temperature changes. New simulations should involve multiple models and volcanic forcing estimates, larger ensemble sizes, and more detailed examination of the sensitivity to eruption-specific differences in the radiative properties, horizontal and vertical dispersion, and size distributions of twenty-first-century volcanic aerosols.

We note that systematic forcing errors in CMIP-5 simulations of historical climate change are not confined to the treatment of volcanic aerosols. Errors are also likely to exist in the treatment of recent changes in solar irradiance ${ }^{9}$, stratospheric water vapour ${ }^{10}$, stratospheric ozone $e^{29,30}$ and anthropogenic aerosols ${ }^{11}$. Even a hypothetical 'perfect' climate model, with perfect representation of all the important physics operating in the real-world climate system, will fail to capture the observed evolution of climate change if key anthropogenic and natural forcings are neglected or inaccurately represented. It is not scientifically justifiable to claim that model climate sensitivity errors are the only explanation for differences between model and observed temperature trends. Understanding the causes of these differences will require more reliable quantification of the relative contributions from model forcing and sensitivity errors, internal variability, and remaining errors in the observations.

\section{Methods}

We use observational TLT results from Remote Sensing Systems in California ${ }^{13}$ (RSS; http://www.remss.com/data/msu/data) and the University of Alabama at Huntsville $^{14}$ (UAH, http://vortex.nsstc.uah.edu/data/msu). Model TLT data are from ALL + 8.5 simulations performed with 28 different CMIP-5 models (Supplementary Tables 1-3). Six of these models have multiple realizations of the ALL +8.5 simulation, yielding a total of 41 realizations of externally forced TLT changes over 1979 to 2012. Model simulation output used in the calculation of synthetic TLT information was downloaded from a portal of the Earth System Grid Federation (http://pcmdi9.llnl.gov/). The statistical method used for removing ENSO and volcano signals from modelled and observed tropospheric temperature data is described in refs 20,21. Application of this approach requires an index characterizing ENSO variability. Here, the selected index was the spatial average of sea surface temperature changes over the Niño 3.4 region, which was computed from version 3b of the NOAA Extended Reconstructed Sea Surface Temperature data set $^{23}$ (http://www.ncdc.noaa.gov//ersst/\#grid) and from the CMIP-5 ALL + 8.5 simulations. The SAOD data in Fig. 2a and 3 are an updated version of information published in ref. 24. The Clouds and Earth's Radiant Energy System (CERES) net clear-sky SW radiation data plotted in Fig. $2 b$ are available at http://ceres-tool.larc.nasa.gov/ord-tool/, and are documented in ref. 26. All TLT results shown in the figures in the main text (except in Fig. 1a, which gives 'raw' TLT results) rely on TLT data from which ENSO-induced variability was statistically removed with a volcanic signal decay time of $\tau=40$ months. The Supplementary Methods provides a full description of: all observational and model TLT data sets used here; the statistical method for removing ENSO-induced TLT variability; the tests applied to assess the statistical significance of volcanically induced signals in observational TLT and SW data; and details of the CanESM2 and GISS-E2-R Vol21c simulations.

Received 29 November 2013; accepted 23 January 2014; published online 23 February 2014

\section{References}

1. Solomon, S. et al. The persistently variable 'background' stratospheric aerosol layer and global climate change. Science 333, 866-870 (2011).

2. Fyfe, J. C., von Salzen, K., Cole, J. N. S., Gillett, N. P. \& Vernier, J-P. Surface response to stratospheric aerosol changes in a coupled atmosphere-ocean model. Geophys. Res. Lett. 40, 584-588 (2013).

3. Santer, B. D. et al. Separating signal and noise in atmospheric temperature changes: The importance of timescale. J. Geophys. Res. 116, D22105 (2011).

4. Fyfe, J. C., Gillett, N. P. \& Zwiers, F. W. Overestimated global warming over the past 20 years. Nature Clim. Change 3, 767-769 (2013)

5. Santer, B. D. et al. Identifying human influences on atmospheric temperature. Proc. Natl. Acad. Sci. USA 110, 26-33 (2013).

6. Meehl, G. A., Arblaster, J. M., Fasullo, J. T., Hu, A. \& Trenberth, K. E. Model-based evidence of deep-ocean heat uptake during surface-temperature hiatus periods. Nature Clim. Change 1, 360-364 (2011).

7. Kosaka, K. \& Xie, S-P. Recent global-warming hiatus tied to equatorial Pacific surface cooling. Nature 501, 403-407 (2013).

8. Haywood, J. M., Jones, A. \& Jones, G. S. The impact of volcanic eruptions in the period 2000-2013 on global mean temperature trends evaluated in the HadGEM2-ES climate model. Atmos. Sci. Lett. http://dx.doi.org/10.1002/asl2.471 (2013).

9. Kopp, G. \& Lean, J. L. A new, lower value of total solar irradiance: Evidence and climate significance. Geophys. Res. Lett. 38, L01706 (2011).

10. Solomon, S. et al. Contributions of stratospheric water vapour to decadal changes in the rate of global warming. Science 327, 1219-1223 (2010).

11. Shindell, D. T. et al. Radiative forcing in the ACCMIP historical and future climate simulations. Atmos. Chem. Phys. 13, 2939-2974 (2013).

12. Morice, C. P., Kennedy, J. J., Rayner, N. A. \& Jones, P. D. Quantifying uncertainties in global and regional temperature change using an ensemble of observational estimates: The HadCRUT4 data set. J. Geophys. Res. 117, D08101 (2012).

13. Mears, C., Wentz, F. J., Thorne, P. \& Bernie, D. Assessing uncertainty in estimates of atmospheric temperature changes from MSU and AMSU using a Monte-Carlo technique. J. Geophys. Res. 116, D08112 (2011).

14. Christy, J. R., Norris, W. B., Spencer, R. W. \& Hnilo, J. J. Tropospheric temperature change since 1979 from tropical radiosonde and satellite measurements. J. Geophys. Res. 112, D06102 (2007).

15. Cowtan, K. \& Way, R. G. Coverage bias in the HadCRUT4 temperature series and its impact on recent temperature trends, Quart. J. Roy. Met. Soc. http://dx.doi.org/10.1002/qj.2297 (in the press). 
16. Taylor, K. E., Stouffer, R. J. \& Meehl, G. A. An overview of CMIP5 and the experiment design. Bull. Amer. Meteor. Soc. http://dx.doi.org/10.1175/BAMS-D-11-00094.1 (2012).

17. Robock, A. Volcanic eruptions and climate. Rev. Geophys. 38, 191-219 (2000).

18. Sato, M., Hansen, J. E., McCormick, M. P. \& Pollack, J. B. Stratospheric aerosol optical depth, 1850-1990. J. Geophys. Res. 98, 22987-22994 (1993).

19. Ramaswamy, V. et al. Anthropogenic and natural influences in the evolution of lower stratospheric cooling. Science 311, 1138-1141 (2006).

20. Wigley, T M L., Ammann, C. M., Santer, B. D. \& Raper, S C B. The effect of climate sensitivity on the response to volcanic forcing. J. Geophys. Res. 110, D09107 (2005).

21. Santer, B. D. et al. Accounting for the effects of volcanoes and ENSO in comparisons of modeled and observed temperature trends. J. Geophys. Res. 106, 28033-28059 (2001).

22. Thompson, D W J., Wallace, J. M., Jones, P. D. \& Kennedy, J. J. Identifying signatures of natural climate variability in time series of global-mean surface temperature: Methodology and insights. J. Clim. 22, 6120-6141 (2009).

23. Smith, T. M., Reynolds, R. W., Peterson, T. C. \& Lawrimore, J. Improvements to NOAA's historical merged land-ocean surface temperature analysis (1880-2006). J. Clim. 21, 2283-2296 (2008)

24. Vernier, J.-P. et al. Major influence of tropical volcanic eruptions on the stratospheric aerosol layer during the last decade. Geophys. Res. Lett. 38, L12807 (2011).

25. R. R.Neely III, et al. Recent anthropogenic increases in $\mathrm{SO}_{2}$ from Asia have minimal impact on stratospheric aerosol. Geophys. Res. Lett. 40, http://dx.doi.org/10.1002grl.50263 (2013).

26. Loeb, N. G. et al. Towards optimal closure of the earth's top-of-atmosphere radiation budget. J. Climate 22, 748-766 (2009).

27. Muller, R. http://www.nytimes. com/2013/09/26/opinion/a-pause-not-an-end-to-warming.html? r=0

28. Christy, J. R. Testimony in Hearing before the Subcommittee on Energy and Power, Committee on Energy and Commerce, House of Representatives, March 8, 2011. http://republicans.

energycommerce.house.gov/Media/file/Hearings/Energy/030811/Christy.pdf
29. Hassler, B. et al. Comparison of three vertically resolved ozone data sets: Climatology, trends and radiative forcings. Atmos. Chem. Phys. 13, 5533-5550 (2013).

30. Eyring, V. et al. Long-term ozone changes and associated climate impacts in CMIP5 simulations. J. Geophys. Res. 118, 5029-5060 (2013).

\section{Acknowledgements}

We acknowledge the World Climate Research Programme's Working Group on Coupled Modelling, which is responsible for CMIP, and we thank the climate modelling groups for producing and making available their model output. For CMIP, the US Department of Energy's Program for Climate Model Diagnosis and Intercomparison (PCMDI) provide coordinating support and led development of software infrastructure in partnership with the Global Organization for Earth System Science Portals. J-P. Vernier (NASA Langley) and M. Sato (GISS) supplied updated SAOD data. T.M.L. Wigley (University of Adelaide), N. Gillett (Canadian Centre for Climate Modelling and Analysis), A. Robock (Rutgers University), K. Trenberth (National Center for Atmospheric Research) and S.F.B. Tett (University of Edinburgh) provided helpful comments. At PCMDI, work by B.D.S., J.P., M.Z. and K.E.T. was performed under the auspices of the U.S. Department of Energy under contract DE-AC52-07NA27344; C.B. was supported by the DOE/OBER Early Career Research Program Award SCW1295.

\section{Author contributions}

B.D.S., C.B., M.Z., C.M., S.S., G.A.S., J.C.F. and K.E.T. designed the analysis of model simulations and observational data. B.D.S., C.B. and M.Z. performed the analysis. G.A.S., J.C.F., J.N.S.C. and L.N. designed, completed and analysed the Vol21c integrations. J.P. calculated synthetic MSU temperatures. C.M. and F.J.W. contributed MSU temperature data. All authors wrote the manuscript.

\section{Additional information}

Supplementary information is available in the online version of the paper. Reprints and permissions information is available online at www.nature.com/reprints. Correspondence and requests for materials should be addressed to B.D.S.

\section{Competing financial interests}

The authors declare no competing financial interests. 